\title{
Application of Chinese Traditional Auspicious Patterns in Logo Design
}

\author{
Xue DONG \\ Shandong Women's University
}

\begin{abstract}
As an important carrier of Chinese traditional culture, traditional auspicious patterns reflect Chinese culture tradition, social customs, national psychology, aesthetics and her special cosmic view and moral value, and also show the long history and particular charm of Chinese traditional culture. As a particular enterprise visual image symbol, traditional auspicious patterns display its powerful function of information transmission. Its form of expression, rule of structure, artistic conception created and culture connotations included offer a traditional cultural bed and nutrient for logo design. It is the historical responsibility and culture consciousness of every designer to transfer the culture value included by auspicious patterns and classic model to logo design, inherit and innovate, combine the international design rule with Shape, Meaning, and Spirit of traditional auspicious patterns to entrust new vitality to logo design, then design the work consistent with modern society to call the return of traditional culture.
\end{abstract}

KEYWORD: Traditional auspicious patterns; brand; visual image; logo

With the development of economy, logo--the brand visual image which shows brand's core value plays an important role. Chinese traditional auspicious patterns, as a special cultural carrier, inherit the philosophical ideas and aesthetic concept of Chinese nation, bear its good wishes and contain people's original demands and spiritual power thanks to its convention and relatively stable inner connotation. They reflect Chinese culture tradition, social customs, national psychology, aesthetics and her special cosmic view and moral value. Their form of expression, rule of structure, artistic conception created and culture connotations included offer a traditional cultural bed and nutrient for logo design. It is an important means of expressing meanings of modern design to transfer the culture value included by auspicious patterns and classic model to logo design.

\section{INTRODUCTION OF CHINESE TRADITIONAL AUSPICIOUS PATTERNS}

As for tradition, Professor Zhao Daoyi defines it in the this way: "Chuan" means transmit and spread, and "Tong" means the successive system. "Tradition" is the transmitted thoughts, morals, human relations, styles, arts, rules and regulations of a country or a nation. Compacting the psychology and customs of all the nations at every age, traditional culture is the soul, disposition and philosophical concept integrated in art creation, while traditional auspicious patterns is the carrier of Chinese culture, whose spiritual pursuit influences the development of logo design.

Being treasure of our traditional culture, auspicious patterns transmit Chinese traditional abstract concepts and conventional habits through tangible visual forms, and create a new special timeless culture. Praying for good fortune and obtaining happiness, pursuing good fortune and avoiding disaster is the tradition in our country, and also the centralized expression of ancient people pursing universe and the unity of heaven and man. Chinese traditional auspicious patterns are formed and developed around the historical theme of auspiciousness. Life and inheritance, pursuing good fortune and avoiding disaster is their unchangeable theme, which are designed artfully, vivid and lovely, of rich national color. Chinese auspicious art, vivid and lively, with rich humanity connotations, is the concrete expression of Chinese traditional culture and customs. The ancient people expressed their pursuit of good life, their best wishes for descendants through auspicious patterns. They weaved beautiful brocades, vivid and lovely, full of love, or simple and plain which were transmitted from generation to generation, exerting profound and lasting influence on social culture and arts. 


\section{CULTURAL CONNOTATIONS OF CHINESE TRADITIONAL AUSPICIOUS PATTERNS}

Just because auspicious patterns possess the symbolic conventional meaning, they are deeply liked by people. Chinese people's conservative and orbicular thinking mode and three main school-Confucianism, Taoism and Buddhism determine that emotions are expressed in the way of expressing meaning, reason and feelings through images. Design methods and expressive means endow traditional auspicious patterns with rich symbolic meanings. Full of connotations but without being showed is the target pursued by modern and ancient poets, painting, as well as other arts. Auspicious patterns of every stages influence Chinese people's lives and souls greatly. It can be pointed out that auspicious patterns, closely related to a country's religion, politics, economy, and aesthetic psychology, related to totem belief of primitive people for life and reproduction, are the remarkable wisdom created by the whole Chinese nation through thousands of years.

\subsection{The believed life and reproduction power carved the historical track of traditional auspicious patterns.}

"The boundless and remote prehistorical history is just like a great persistent master propelled by powerful belief carving indelible soul track on countless culture relics."[1] Several thousand years ago, our ancestors began to use patterns to express thoughts and communicate emotions. The oldest traditional auspicious patterns are not only of strong artistic feeling, but more importantly, they were specific objects bearing people's belief. In ancient times, people were confused about natural phenomena, and frightened a lot by natural changes, natural environment, invasion of beast, life and death of themselves. "Upper cave men's strong pursuit of life consciousness and heaven, mysterious man-faced fish pattern of Banpo pottery basin, all deliver the message of divinities."[2] The earliest auspicious concept came from people's reverence towards life, admiration for nature, totem and reproduction, and closely related to Chinese people's peculiar way of thinking as well as the strong symbolic awareness and tradition. Conversing hope of life and pursuit of happiness into symbolic patterns to create auspicious patterns which can wipe off devils and get the blessing from Gods.

\subsection{Profound ancient philosophic concept builds spiritual basis of traditional auspicious patterns.}

"There is no purely abstract or purely realistic traditional Chinese pattern. They are beautiful but not raffish, pleasure but not crazy, containing deep understanding of Chinese philosophy."[3]Auspicious patterns reflect Chinese wisdom essence of thousands of years. Confucianism, Taoism and Buddhism all influence auspicious patterns greatly. Containing and influenced by modeling and aesthetic consciousness of Chinese traditional culture, traditional auspicious patterns inherit and pass on traditional culture of unique national charm. Integrating culture into logo design will bring tremendous cultural value and economic value to enterprises. Design needs understanding and decomposing traditional culture, promote local culture, refer to shape and meaning of traditional auspicious patterns, and create logo of oriental charm.

\section{APPLICATION OF CHINESE AUSPICIOUS PATTERNS IN LOGO DESIGN}

We are going through a large-scale brand establishment and Chinese economic reform is guiding Chinese products and service to move forward in international competition. All enterprises are contending for engagement in international market to make more additional value through building brand. Learning from brand build in the west, many enterprises introduce CIS (Corporate Identity system), also called enterprise image strategy and enterprise image scheme whose first element is logo design. Logo plays an important role in enterprise visual image establishment. As a visual sign, $\operatorname{logo}$ can familiarize the public more with enterprises' cultural and symbolic meaning. Logo design of characteristic personality is good for enterprise's brand being identified and remembered. One source of characteristic personality is Chinese figures and connotations of Chinese traditional auspicious patterns.

Many countries in the world establish their peculiarity and cultural identity, just like the Great Wall on behalf of China, abattoir of Roman, sakura of Japan, olive branch of Greece, xiezhi of Seoul, all the symbolic architectures and objects mentioned above can highlight the country's cultural connotation and accepted by us. Japanese Han Zongli who thinks "the essence of design is creation and tradition itself is from creation. So away from tradition, design is imaginable."[4] puts national design into western design. The products designed by him are enduring of beauty and connotation both of west and east.

\subsection{The form inheritance of traditional auspicious patterns in logo design}

Shape refers to the expressive method of intrinsic meaning included. It is the externalization and 
materialization of intrinsic connotation, the carrier. [5]Generally, shape is the image outline and structure of patterns, and it is a medium that we communicate with perceived objective world.

Firstly, extracting the texture of traditional auspicious patterns is to extract composition rule and modeling method of traditional patterns directly. Designers also want to familiarize people with the emotions included by logo through well-known traditional auspicious patterns and retain the organization structure of shape. For example, Tai Ji uses black and white helix structure to describe positive and negative circulatory world which represents the beauty of opposite and complementary cosmos. It is an unfailing format of Chinese auspicious patterns thousands of years. The logo of Xiwu department store designed by Chen Youjian (drawing 1) adopts the basic format of Tai Ji. When Jin Daiqiang was designing the poster (drawing 2) for Czech Republic Jan Rajich Senior's 80 birthday anniversary, he utilized the common point of circular pattern and Chinese character "Wan" pattern, searched character pattern of "Shou" composed by four groups of circle round, combined with the original work and applied to the poster directly and integrated two different cultures of designers from different areas. Chen Youjian designed company loge using four happy persons for reference (drawing 3 ). The writer took three-legged wine glass of Shang dynasty as outline of Tianyanglou Hotel logo, transforming the forms of characters to express the essential attribute of enterprise-hotel (drawing 4).

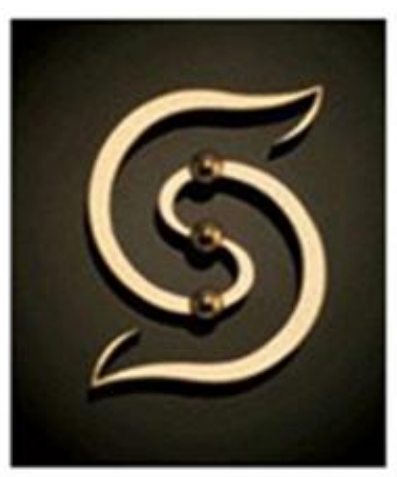

Drawing 1. Xiwu Department Store

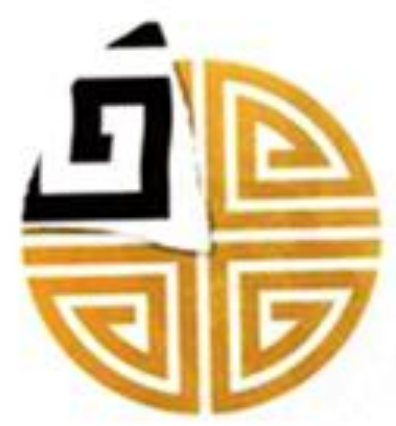

Drawing 2. Jin Daiqiang's poster design

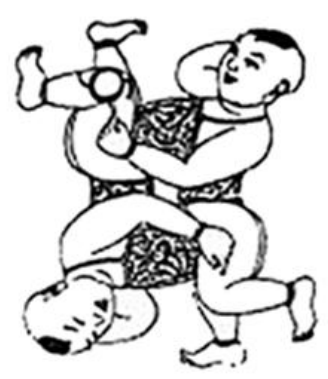

Drawing 3. Four happy men

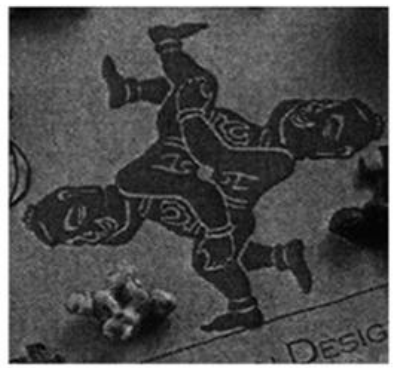

Chen Youjian company logo

Secondly, extract, purify and modernize the representative elements of the original patterns from modern aesthetic perspective. "Because of the feeling and thinking of Chinese traditions, I always pay attention to our culture root when designing". Many logos designed by Jin Daiqiang are influenced by traditional auspicious patterns. It can be seen from the logo of Jin \& Liu Design Company that there is traditional auspicious pattern "square pattern" (drawing 5). He took square pattern as basic framework to extract and recreate drawing and endow company $\log 0$ with oriental national personality.
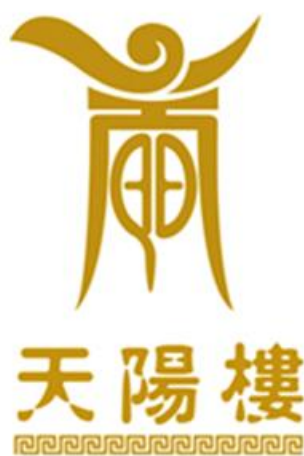

Drawing 4. Tianyanglou Hotel design

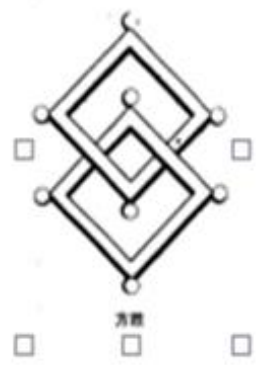

Drawing 5. Square pattern and Jin \& Liu Design Company

\subsection{Logo design's inheritance of "meaning" of traditional auspicious patterns}

The narrow meaning of "meaning" is moral and symbol, i.e. the conventional nation meaning of traditional auspicious patterns. Logo design can take patterns' symbolic and cultural meaning. For example, lotus implies honest and upright, and dragon implies Chinese nation spirit and sovereign 
power as well as luxury. Actually they deliver a message, an attitude, a behavior and a cultural position in a more implicit method. That is the extension of traditional symbol "meaning" in modern design works.

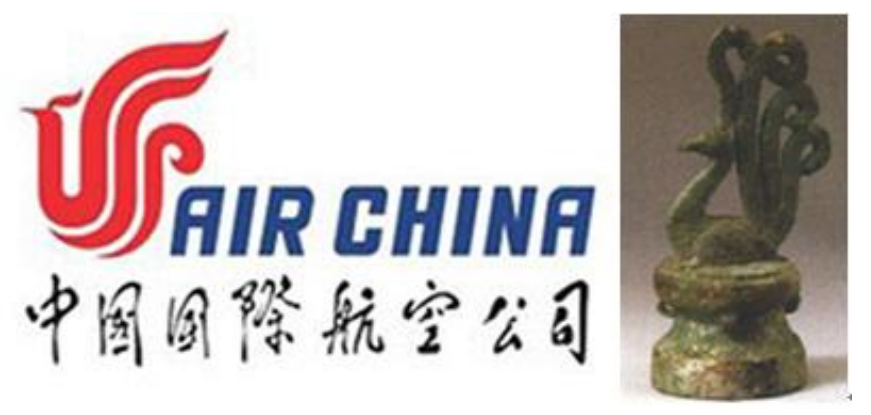

Drawing 6. Logo of Air China International Corp.

The logo of Air China International Corp. (drawing 6) that we are familiar with resorts to the modeling of phoenix with the meaning of auspiciousness. Phoenix is the king of birds symbolizing dignity, auspiciousness and peace by which the corporation expresses the meaning of peace, auspiciousness and happiness. The logo of Yunnan Baiyao Corp. (drawing 7) adopts Baoxiang Flower of Tang dynasty whose decorative design is luxurious and symbolizes auspiciousness and prosperous plants in its growing area. The middle precious bottle gourd symbolizes life-saving and expiration and inspiration of elixir of life, expressing the implied meaning of devotion to people, auspiciousness and peace.

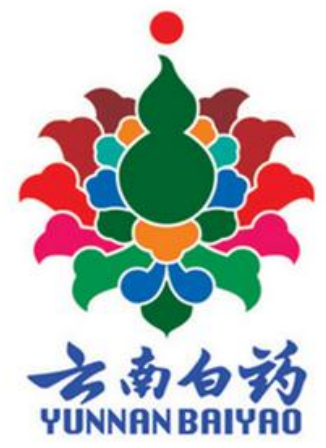

Drawing 7. Logo of Yunnan Baiyao

\subsection{Logo design's inheritance of "spirit" of traditional auspicious patterns}

"Spirit" is a concrete and abstract artistic conception included in logo design which can't be seen but can be perceived. Logo design should take shape as the basis and similarity in spirit as purpose, apply shape and meaning comprehensively to convey a romantic charm surpassing logo itself and an associative beauty. The understanding of meaning contained between the lines reflects aesthetic taste that Chinese art pursues.
Chen Youjian's works are characterized with eastern and western taste and charm. His design philosophy integrates western and eastern culture reasonably, blend western aesthetics and eastern culture successfully, and endow works with traditional taste and fashion. Logo of tea (drawing 8) is the classic work in Chinese design circle, soft and moist, mild and indirect, conveying an artistic conception of leisure and Buddhism. With the help of Buddha's hand, logo's connotation is highlighted. When looking at the pattern, rather than the pattern itself, people find the associative meaning of comfort, Buddhism, and primitive simplicity. The visual image design of Cultural festival of the waterside town north of the Yangtze River \& 10th anniversary of Liaocheng City (drawing 9) extracts our country's traditional auspicious patterns. The modeling of Cloud pattern and Ruyi applied the romantic charm of auspicious clouds reflect purple Han palace, spring scenery draw Qin Chuan light", adding "best wishes, peace and propitious omen" to 10th anniversary celebration.

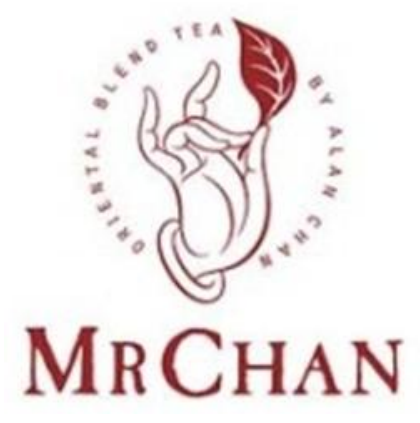

Drawing 8. Logo of Tea

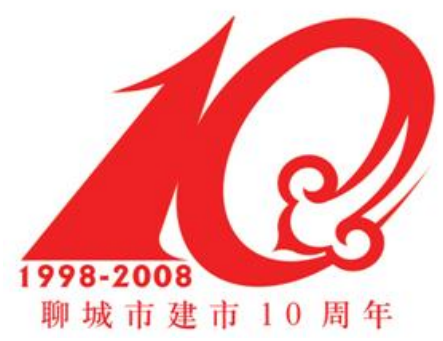

Drawing 9. 10th anniversary of Liaocheng City

\section{CONCLUSION}

In the age of international homogenization, people can draw nutrient from auspicious patterns to design peculiar logo, build visual image, spread enterprise culture and spirits, and then shape its own brand. Extensive subjects, peculiar forms and rich connotations of auspicious patterns provide modern logo design with national nutrient. Only deeply rooted in traditional culture and with the help of intersperse of auspicious patterns, the big tree of logo design can be prosperous. The beauty of pattern style and artistic conception of Chinese traditional 
auspicious patterns give new enlightenment to the beauty of form and graph of logo design: integrate national traditional culture into modern logo design naturally and clearly, transfer cultural value and classic modeling of patterns to logo connotation and design to recreate. Only in this way can fuse meaning, surpass shape and create new traditional pattern culture.

Designers should adhere to Chinese national tradition, inherit and develop Chinese culture creatively. Only after they comprehend artistic conception of oriental auspicious patterns when applying them, draw the nutrient from foreign arts, integrate with western forms and rules, incorporate and digest things of diverse natures, can they design logo of Chinese national style. Designing nationally accepted works of modern sense through learning and referring, absorbing and co-building, waking up traditional culture, conflicting visual meaning with symbolic meaning, tradition with modern plays a vital role in strengthening enterprise brand construction and developing competitiveness, and also is the historical responsibility and culture consciousness of every designer.

\section{REFERENCES}

[1] Chen Jiangfeng, Syncretism between Heaven and Man and Huaxia Cultural Tradition. Life- Reading. New Sanlian Bookstore, 1996:4

[2] Chen Jiangfeng, Syncretism between Heaven and Man and Huaxia Cultural Tradition. Life. Reading. New Sanlian Bookstore, 1996:4

[3] Yang Li. On Application of Traditional Patterns in Modern Design. Academic Journal of Hunan Commercial College. 2003,(6)

[4] Hang Jian, Jin Daiqiang. Bauhaus Road: History, Relic, World and China. Jinan: Shandong Art Press. 2010.5:106115

[5] Xie Yanping. Application of Chinese Characters in Modern Logo Design. Chongqing: Graduation Thesis of Chongqing University. 2006 